\title{
The Use of Social Media by Dental Students for Communication and Learning: Two Viewpoints
}

\author{
Viewpoint 1: Social Media Use Can Benefit Dental Students' \\ Communication and Learning
}

Tracy L. de Peralta, O. Fields Farrior, Natasha M. Flake

\section{Viewpoint 2: Potential Problems with Social Media Outweigh Their Benefits for Dental Education}

\begin{abstract}
Desmond Gallagher, Cristiano Susin, John Valenza
Abstract: Social media have become a major part of an interconnected society, impacting personal and professional lives. This Point/Counterpoint presents two opposing viewpoints on the question of whether social media should be used in dental education as a learning and communication tool for dental students. Viewpoint 1 argues that social media benefit student learning and should be used as a tool in dental education. This argument is based on evidence concerning use of social media and improved learning across health professions, improved peer-peer communication in clinical education, improved engagement in interprofessional education (IPE), and provision of a mechanism for safe and improved communication between practitioners and patients, as well as faculty and students. Viewpoint 2 argues that potential problems and risks in using social media outweigh any benefits found in learning and therefore social media should not be used as a tool in dental education. This viewpoint is supported by evidence of negative effects on learning, the establishment of a negative digital footprint in the public's view, risk of privacy violations when using social media, and the new phenomenon of Internet addiction with its negative physiological effects on social media users.

Tracy L. de Peralta, DMD, PhD, MClinEd, is Clinical Associate Professor and Director of Curriculum and Assessment Integration, University of Michigan School of Dentistry; O. Fields Farrior, DMD, MS, is Associate Clinical Professor and Associate Dean of Clinical Education and Patient Care, University of New England College of Dental Medicine; Natasha M. Flake, DDS, PhD, MSD, is Associate Professor and Director of Predoctoral Endodontics, University of Washington School of Dentistry; Desmond Gallagher, DDS, MA, MFGDP (UK), is Assistant Professor and Executive Associate Dean, University of the Pacific Arthur A. Dugoni School of Dentistry; Cristiano Susin, DDS, MSD, PhD, is Professor and Chair, Department of Periodontology, University of North Carolina at Chapel Hill School of Dentistry; and John Valenza, DDS, FAGD, is Professor and Dean, University of Texas School of Dentistry at Houston. Direct correspondence to Dr. Tracy de Peralta, University of Michigan School of Dentistry, 1011 N. University Avenue, Ann Arbor, MI 48109; 734-764-8979; tdeperal@umich.edu.
\end{abstract}

Keywords: dental education, communication and interpersonal skills, professional behavior, social media, educational technologies

Submitted for publication 10/26/18; accepted 11/19/18; first published online 3/25/19 doi: 10.21815/JDE.019.072

$\mathrm{S}$ ocial media are defined by Ventola as a collection of Internet-based tools that create a platform for individuals and populations to assemble and communicate, enabling easy sharing of information, ideas, messages, and images and collaborating in real-time. ${ }^{1}$ According to Parkinson and Turner, examples of social media were first seen in the late 1960 s with the first major commercial
Internet server (Compuserve); however, the widespread adoption of social media occurred from 2003 to 2008 with the rise of MySpace and Facebook. ${ }^{2}$ Hollinderbaumer et al.'s systematic review found a variety of examples of social media being used in medical education, including blogs, social messaging, audience response systems, location-based networks, podcasting, wikis, media sharing, and social networking sites. ${ }^{3}$ 
Reasons for dental faculty use of social media were reported by Arnett et al. to range from communicating with colleagues and students to promoting administrative processes in a learning environment. ${ }^{4}$

This Point/Counterpoint article will focus on social media that support or can support both student learning and patient-practitioner and studentfaculty communication. Examples of social media frameworks and tools involved in digital learning environments are the following: social networking (e.g., Facebook, Twitter), blogging platforms (e.g., Word Press), RSS feeds (e.g., Knowyourteeth), niche networks (e.g., ELGG.com), videos (e.g., YouTube), mash-ups (e.g., Yahoo!Pipes), social bookmarking (e.g., Citeyoulike), wikis (e.g., Wikipedia), crowdsourcing (e.g., PatientsLikeMe), and virtual environments (e.g., Second Life). ${ }^{5}$ Studies in dental, nursing, and medical education have found benefits in use of social media tools in clinical education..$^{5-7}$ Cheston et al.'s systematic review of social media use in medical education found that these technologies promoted knowledge transfer, attitudes, skills, learner engagement, feedback, and professional development. ${ }^{7}$ Spallek et al. reported that patients are turning to social media to report their health care experiences on services such as Angie's List and RateMDs. ${ }^{8}$ However, risks have been identified, such as creation of a negative digital footprint, compromised professional relationships, litigation due to misconduct, and detrimental physiological effects for users based on dopamine release. Our two viewpoints examine the evidence on opposing sides of this issue.

\section{Viewpoint 1: Social Media Use Can Benefit Dental Students' Communication and Learning}

Social media have been found to promote student learning in health professions education. Educators who have integrated social media into their teaching methods have demonstrated that their students were motivated by content obtained from social media, promoting positive behavioral changes and imparting fundamental knowledge for comprehensive health care of the public. ${ }^{9-11}$ Other studies have found that learners' satisfaction with social media interventions was positive. ${ }^{7,12-15}$ One study examining the effect of social media use on learning reported that students who were more heavily engaged in blog-based discussion of learning content had higher grades at the end of a course than those who had posted less on the same discussion forum. ${ }^{16}$ Cheston et al.'s systematic review found that students who used social media in clinical education perceived having enhanced collaboration with their peers, improved professional development, improved career advancement, and more supportive learning communities. $^{7}$ In that review, students reported that social media tools provided a valuable means of connecting them to resources, enhancing their evidence-based approach to learning. Knosel et al. reported that YouTube videos offered new educational opportunities in dental education, although they also noted that those opportunities in 2011 were underdeveloped and underestimated in their potential for educational impact. ${ }^{17}$

\section{Enhancing Learner Engagement}

Certain forms of social media can promote student engagement with learning materials and with each other. Ventola found that a significant percentage of educational programs in medicine, pharmacy, nursing, and dentistry were using social media as a learning tool in their curricula. ${ }^{1}$ In a study of 170 nursing students, $92.4 \%$ reported perceiving that podcasting of lecture material had a positive impact on their collaborative learning. ${ }^{12}$ Another study reported that using social media tools provided learning opportunities for students to better engage with the learning material itself. ${ }^{9}$ In their systematic review, Hollinderbaumer et al. called the integration of social media in clinical education a modern form of self-determined learning, allowing for student self-direction and learning automony. ${ }^{3}$

Furthermore, Evans and Hanes found that dental students perceived that the use of e-logs and discussion boards in an online cultural competence course promoted self-awareness and critical thinking. ${ }^{18}$ Gonzalez et al. used Twitter successfully for teaching and learning in an oral and maxillofacial radiology course, finding that students perceived it was a helpful component of their learning and that it improved the accessibility of the faculty in the course. ${ }^{19}$

\section{Optimizing Communication for Better Patient Care}

Social media may also be used to provide students, faculty, and patients with opportunities to 
interact with each other they would not otherwise have. In a study of the development of campusbased relationships using email and instant messaging (IM) networks such as WhatsApp to enhance student-student and student-faculty communication, Khatton et al. found that students perceived communication with peers as good when using these online tools. ${ }^{20}$ Furthermore, Salajan and Mount successfully developed and implemented a Wiki-based application as an educational tool to promote collaboration in learning for dental faculty, students, and patients. ${ }^{21}$

When ethical guidelines are followed, social media can effectively promote communication between provider and patient, as well as between faculty and students. Chretien et al. described strengths in clinical care when social media were used in accordance with the American Medical Association (AMA) principles of medical ethics. ${ }^{22}$ They found that thoughtful use of secure closed systems with data encryption, by establishing expectations of the online communication process, greatly enhanced patient care through quicker and more direct communication with care providers. Kind summarized the AMA's guidelines about social media use in association with writing about patients, providing health-related content to patients to enhance patient care, and identifying oneself as a care provider in an online exchange. ${ }^{23}$ These rules of professionalism in social media would also apply to faculty-student interactions, promoting communication and providing resources to students in a helpful, fast, and efficient manner.

Regarding social interactions in medical education, Chretien et al. pointed out that both patient and student information must be protected through HIPAA and FERPA compliance. ${ }^{22}$ Seymour et al. used an exploratory initiative to define a new role for dentists in patient education at a time when patients use online sources to answer many of their health care questions. ${ }^{24}$ Ventola described how the University of Rhode Island has connected students to geriatric patients on Facebook to promote students' communication skills and empathy for this population, while helping patients learn to use social media to battle loneliness and reduced social contact associated with later years of life. ${ }^{1}$ A program called Health Innovation Exchange (HIVE) uses social media tools to support interprofessional education across disciplines in a School of Population Health. ${ }^{9}$ These examples illustrate ways that communication promoted through use of social media can benefit patient care.

\section{Viewpoint 2: Potential Problems with Social Media Outweigh Their Benefits for Dental Education}

Negative effects on student learning associated with curricular use of social media have been reported, raising questions about their potential for dental education. In a study of use of Twitter as an educational tool in pharmacy, $71 \%$ of students said it was distracting because of their desire to read general content on Twitter rather than the course material. ${ }^{25}$ In a survey of dental hygiene programs, Beebe et al. found that most students and faculty members preferred a hybrid course with both online and faceto-face instruction, whereas only $8 \%$ or less reported that online alone was a good educational format. ${ }^{26}$ In that study, faculty members reported that barriers to using social media for course instruction included technical difficulties and students' using the technology for non-academic purposes during class.

\section{Negative Digital Footprint}

Inappropriate boundaries in patient-practitioner relationships have been associated with using social media. Concerns exist around the digital footprint left behind with inappropriate use of social media by health professionals and students as they communicate in a public sphere. ${ }^{27}$ This negative footprint develops when there is a momentary lapse in judgment, and actions are spread rapidly beyond the intended audience. Oakley and Spallek provided examples of unprofessional behavior in which integration of professional and private content posted on social media caused destruction and confusion for patients who were exposed to this content, while leaving a very damaging digital footprint for students and dental practitioners. ${ }^{28}$ The digital footprint is not controllable: once content is created, it may not be able to be deleted. Appropriate guidance on professionalism such as the AMA policy needs to be followed, so that social media is used as a platform for health professionals to share information quickly and reach millions of people easily in the interest of promoting health, while not damaging relationships between individuals. ${ }^{28-30}$ 


\section{Regulation and Professional Boundaries}

The public nature of some social media leads to ethical concerns, such as violations of patient confidentiality. The AMA published a policy on professionalism in the use of social media, in the hope of preventing the damaging effects social media interactions can have on patients and students. ${ }^{29}$ It is essential that we as health professionals maintain patient confidentiality, using appropriate privacy settings and accepting that all posted material should be considered open for public viewing. ${ }^{31}$ Unfortunately, in their survey of social media policies in dental education, Henry and Webb found multiple instances of social media violations, such as HIPAA and patient privacy violations, personal conduct issues, and unprofessional comments about academic dental institutions, faculty, and students. ${ }^{30}$ To help dental educators understand the boundaries of protected speech, Parkinson and Turner published a review of legal cases that led to current social media policies and highlighted the pitfalls that can exist with poorly regulated social media use. ${ }^{2}$ Unfortunately, technology is moving faster than the judicial system. Kind et al. found that social media policies at U.S. medical schools are not always clear in using social media as protected speech in an educational environment, posing risks to both academic dental institutions and their students. ${ }^{32}$

As health professionals, we clearly need to separate our online personal and professional content. When setting up monitoring systems for social media use to uphold our institutional codes of conduct and to support our school missions, Cain and Fink suggested that we might be creating a "duty of due care" toward our students..$^{33}$ In creating this situation, our institutions are heightening our responsibility to prevent harm for students, and we open ourselves to an increased likelihood of litigation associated with social media use, as described by Steinbach and Deavers. ${ }^{34}$ Furthermore, Bahner et al. cautioned that, if educators want to use public social media such as Twitter for educational purposes, they cannot require their students to register to use these public tools and therefore may not always have access to the entire student cohort. ${ }^{35}$ As Bahner et al. explained, educators may not be able to control their followers on social media as the technology is public, which can also dilute any data being collected about students' use of the tool.

\section{Risk of Physical Addiction}

The use of social media for educational purposes could possibly contribute to the new phenomenon of Internet addiction. According to Grant et al., Internet use can activate specific sites in the brain, releasing dopamine and ultimately resulting in a physiological addiction to this biological substance. ${ }^{36}$ In their summary of psychiatric research, Cash et al. reported that "Internet addiction disorder" had impacted lives by causing neurological complications, psychological disturbances, and social problems. ${ }^{37}$ Other researchers reported that Internet use may lead to dopamine release in the nucleus accumbens, which is one of the pleasure sites of the brain specifically involved in addiction. ${ }^{38,39}$ Another study found evidence of a genetic link between dopaminergic neurotransmission and Internet addiction. ${ }^{40}$ Therefore, using social media in dental education may be particularly detrimental to any students who are predisposed to addictive behaviors since these biochemical effects can have profound effects if the seeking of connectedness and the avoidance of social isolation cause a spiral of negative outcomes. If these technologies are incorporated into dental education, it is imperative to provide support for those individuals at higher risk of experiencing negative effects of social media.

\section{Response by Drs. de Peralta, Farrior, and Flake to Viewpoint 2:}

Viewpoint 2 contends that problems with social media outweigh the benefits of its use in dental education. We respond that, like all tools, there is an indication for use, and social media have to be used responsibly. It is our responsibility as educators to teach students how to use social media in a professional manner. Most dental students are currently using social media, and after graduation, most new dentists will use it to promote their practice. The problems pointed out in Viewpoint 2 may exist, but we as educators need to recognize the imperative to teach students about appropriate use of social media as part of their professional development rather than attempting to disallow those technologies. This education must include the regulatory and patient privacy concerns given as reasons against use of social media.

Viewpoint 2 also points out new research into Internet addition. We argue that work-life balance is important for both students and faculty, and we have observed that dental programs have begun to incorporate instruction in tools to aid work-life balance into their curricula. The importance of limiting 
screen time needs to be part of this instruction as well. We maintain that the use of social media as an adjunctive aid in dental education should be done in a manner that does not encroach upon the lives of students or faculty. Although the issues Viewpoint 2 raises are real, we disagree that the potential problems with social media use outweigh their benefits. It is our belief that learners will benefit if dental education embraces the use of social media and teaches students how the tools can be used in a productive, responsible, and safe manner.

\section{Response by Drs. Gallagher, Susin, and Valenza to Viewpoint 1:}

Viewpoint 1 argues that social media should be used as a tool to enhance learning in dental education because they benefit dental students through enhancing student engagement and optimizing communication for better patient care. We contend that those points are not supported in the published research on the subject. For example, Viewpoint 1 claimed that Arnett et al. supported the use of social media in dental education, but that study also reported concerns expressed by educators about the distraction social media poses in a learning environment. ${ }^{4}$ In fact, Smith reported there are gaps in understanding how social media are influencing the classroom environment. ${ }^{41}$ We caution against drawing conclusions from only those studies showing positive effects.

While we acknowledge there may be some benefits of social media in dental education, we strongly argue that there are far too many risks associated with social media use to support wide implementation. Even if training is provided in proper use of social media, a single lapse in judgement would risk damaging the reputation of our profession, as well as that of the dental student, having detrimental effects on the future of both. Tryon and Logan questioned whether restorative or punitive steps need to be taken when misconduct associated with social media occurs in a dental school setting, whether for private or curricular use ${ }^{42}$ No academic dental institution should be faced with such questions or actions for their students. Therefore, social media should be avoided as an educational tool in dental education in the best interest of our future students and to provide safe and ethical patient care in our educational environments.

\section{Acknowledgments}

This work represents the authors' efforts as part of their Fellowship in the ADEA Leadership
Institute. We would like to thank the ADEA Leadership Institute administration, coaches, and mentors for their generous support and guidance particularly to our study group and to the entire ADEA Leadership Class of 2018.

\section{Disclosure}

The authors reported no conflicts of interest.

\section{REFERENCES}

1. Ventola CL. Social, medical, and health care professionals: benefits, risks, and best practices. Pharm Ther 2014;39(7):491-520.

2. Parkinson JW, Turner SP. Use of social media in dental schools: pluses, perils, and pitfalls from a legal perspective. J Dent Educ 2014;78(11):1558-67.

3. Hollinderbaumer A, Hartz T, Uckert F. [Education 2.0: how have social media and Web 2.0 been integrated into medical education? A systematic literature review.] GMS Zeitschrift fur Medizinische Ausbildung 2013;30(1):7-12. [In German]

4. Arnett MR, Loewen JM, Romito LM. Use of social media by dental educators. J Dent Educ 2013;77(11):1402-12.

5. McAndrew M, Johnston A. The role of social media in dental education. J Dent Educ 2012;76(11):1474-81.

6. Schmitt T, Sims-Gibbens SS, Booth RG. Social media use in nursing education. Online J Issues Nurs 2012;17(3): article 2.

7. Cheston CC, Flickinger TE, Chisolm MS. Social media use in medical education: a systematic review. Acad Med 2013;88(6):893-901.

8. Spallek H, Turner SP, Donate-Bartfield E, et al. Social media in the dental school environment, part A: benefits, challenges, and recommendations for use. J Dent Educ 2015;79(10):1140-52.

9. Paton C, Bamidis P, Eysenbach G, et al. Experience in the use of social media in medical and health education. Nursing and Health Professions Faculty Research and Publications. 2011. At: repository.usfca.edu/nursing_fac/6. Accessed 12 July 2017.

10. Potts HW. Student experience of creating and sharing material in online learning. Med Teach 2011;33(11):607-14.

11. Varga-Atkins T, Dangerfield P, Brigden D. Developing professionalism through the use of wikis: a study with first-year undergraduate medical students. Med Teach 2011;32(19):824-9.

12. Forbes MO, Hickey MT. Podcasting: implementation and evaluation in an undergraduate nursing program. Nurse Educ 2010;33(5):224-7.

13. Abate LE, Gomes A, Linton A. Engaging students in active learning: use of a blog and audience response system. Med Ref Serv 2011;30:12-8.

14. Calderon KR, Vij RS, Mattana J, Jhaveri KD. Innovative teaching tools in nephrology. Kidney Int 2011;79:797-9.

15. Dinh M, Tan T, Bein K, et al. Emergency department knowledge management in the age of Web 2.0: evaluation of a new concepts. Emerg Med Australas 2011;23:46-53. 
16. Carvas M, Imamura M, Hsing W, et al. An innovative method of global clinical research training using collaborative learning with Web 2.0 tools. Med Teach 2010;32:270.

17. Knosel M, Jung K, Bleckmann A. YouTube, dentistry, and dental education. J Dent Educ 2011;75(12):1558-68.

18. Evans L, Hanes P. Online cultural competency education for millennial dental students. J Dent Educ 2014;78(6):867-75.

19. Gonzalez S, Gadbury-Amyot C. Using Twitter for teaching and learning in an oral and maxillofacial radiology course. J Dent Educ 2016;80(2):149-55.

20. Khatton B, Hill K, Walmsley D. Instant messaging in dental education. J Dent Educ 2015;79(12):1471-8.

21. Salajan FD, Mount G. Leveraging the power of Web 2.0 tools: a Wiki platform as a multimedia teaching and learning environment in dental education. J Dent Educ 2012;76(4):427-36.

22. Chretien KC, Greysen SR, Chretian JP, Kind T. Online posting of unprofessional content by medical students. JAMA 2009;302(12):1309-15.

23. Kind T. Professional guidelines for social media use: a starting point. AMA J Ethics 2015;17(5):441-7.

24. Seymour B, Yang H, Getman R, et al. Patient-centered communication: exploring the dentist's role in the era of e-patients and health 2.0. J Dent Educ 2016;80(6):697-704.

25. Grindrod K, Forgione A, Tsuyui RT. Pharmacy 2.0: a scoping review of social media used in pharmacy. Res Social Adm Pharm 2014;10(1):256-70.

26. Beebe CRR, Gurenlian JR, Rogo EJ. Educational technology for millennial dental hygiene students: a survey of U.S. dental hygiene programs. J Dent Educ 2014;78(6):838-49.

27. Greysen SR, Kind T, Chretien C. Online professionalism and the mirror of social media. J Gen Intern Med 2010;25(11):1227-9.

28. Oakley M, Spallek H. Social media in dental education: a call for research and action. J Dent Educ 2012;76(3):279-87.

29. American MedicalAssociation.AMApolicy: professionalism in the use of social media. At: www.ama-assn.org/ama/ pub/meeting/index.shtml. Accessed 7 Apr. 2011.
30. Henry RK, Webb C. A survey of social media policies in U.S. dental schools. J Dent Educ 2013;78(6):850-5.

31. Thompson LA, Black E, Duff WP, et al. Protected health information on social networking sites: ethical and legal considerations. J Med Internet Res 2011;13(1):e8.

32. Kind T, Genrich G, Sodhi A, Chretien K. Social media policies at U.S. medical schools. Med Educ Online 2010;15:5324.

33. Cain J, Fink JL. Legal and ethical issues regarding social media and pharmacy education. Am J Pharm Educ 2010;74(10):1-8

34. Steinbach S, Deavers L. The brave new world of MySpace and Facebook. Inside Higher Ed. At: www.insidehighered. com/layout/set/print/views/2007/04/03/steinbach. Accessed 22 May 2007.

35. Bahner DP, Adkins E, Patel N, et al. How we use social media to supplement a novel curriculum in medical education. Med Teach 2012;34(6):439-44.

36. Grant JE, Brewer JA, Potenza MN. The neurobiology of substance and behavioral addictions. CNS Spectrums 2006;11(12):924-30.

37. Cash H, Rae CD, Steel AH, Winkler A. Internet addiction: a brief summary of research and practice. Curr Psychiatry Rev 2012;8:292-8.

38. Bai YM, Lin CC, Chen JY. Internet addiction disorder among clients of a virtual clinic (Letter). Psychiatr Serv 2001;52(10):1397.

39. Ko CH, Lui GC, Hsiao S, et al. Brain activities associated with gaming urge of online gaming addiction. J Psychiatr Res 2009;43(7):739-47.

40. Montag C, Kirsch P, Sauer C, et al. The role of the CHRNA4 gene in Internet addiction: a case-control study. J Addiction Med 2012;6(3):191-5.

41. Smith E. A real double-edged sword: undergraduate perceptions of social media in their learning. Comput Educ 2016;103:44-58.

42. Tryon J, Logan N. Dalhousie dentistry students break silence on "Gentlemen's Club" Facebook scandal. Global News, 21 May 2015, updated 22 May 2015. At: globalnews. $\mathrm{ca} /$ news/2010585/dalhousie-dentistry-students-breaksilence-on-gentlemens-club-facebook-scandal/. Accessed 10 Oct. 2018 